\title{
How Does Human Amniotic Membrane Help Major Burn Patients Who Need Skin Grafting: New Experiences
}

\author{
Ali Akbar Mohammadi ${ }^{1}$ and \\ Mohammad Kazem Mohammadi ${ }^{2}$ \\ ${ }^{1}$ Associate Professor of Surgery, Shiraz Burn Research Center, \\ Division of Plastic Surgery, Department of Surgery, \\ Shiraz University of Medical Sciences, Shiraz \\ ${ }^{2}$ Faculty of Science, Ahvaz Branch, Islamic Azad \\ University, Ahvaz
}

Iran

\section{Introduction}

Burns are among the most common traumas in developing countries, which consume large amounts of medical resources. It is important to find an appropriate material for dressing of burn wounds that improves healing and is readily available, easily applicable, and economical and also be protective from infection and desiccation, and facilitate healing. [1] Most burn injuries happen in people with lower socio-economic class. Therefore, reducing the expenses of burn treatment is an important goal alongside healing as the primary aim. [2] Amniotic membrane has been used since 1910 with variable success as a material for burn injury coverage. [3] It has the following advantages:

- readily available in sufficient quantity

- application not associated with immunological problems

- large size

- $\quad$ simple to prepare and sterilize

- no allergic reactions

- up to $15 \%$ reduction of water losses in wounds

- histological structure similar to that of skin $[4,5]$

The disadvantage of the use of amniotic membrane is that there is some risk of viral infection transmission, e.g. hepatitis, syphilis and AIDS. [4]. Two varieties of amniotic membrane are mainly used:

- $\quad$ in Toto (amnion + chorion) on deep burns

- amnion alone (epithelium + basal membrane) on superficial burns[3]

The amnion is a thin semi-transparent tissue forming the innermost layer of the fetal membrane. As fresh amnion carries contamination risk and disease transmission, amnion is collected from placentae of selected and screened donors. Various preservation methods have been introduced, including cryopreservation in liquid nitrogen, preservation in silver 
nitrate, storage in antibiotics solution, glycerol-preserved sheets, dried sheets and gammairradiated sheets. [6]

It has been claimed to be one of the most effective biological skin substitutes used in burn wounds, with efficiency of maintaining low bacterial counts. It also has advantages of reducing loss of protein, electrolytes and fluids, decreasing the risk of infection, minimizing pain, acceleration of wound healing and good handling properties. [6]

Amniotic membrane is readily available and does not present immunological problems and allergic responses. It also reduces water loss.

The risk of the transmission of some viral infections has to be taken into account. Bacterial examinations performed in 20 patients with burn wounds covered with amniotic membrane showed low or no bacterial colonization of the burn surface. It is concluded that amniotic membrane should be more widely used in this particular aspect of burn treatment. [4]

Human amniotic membrane has several interesting physiologic and histologic characteristics which are the basis of its increased use in burn patients. It also has a unique combination of properties, including the facilitation of migration of epithelial cells, reinforcement of basal cellular adhesion and encouragement of epithelium differentiation.

Amniotic membrane is able to modulate stromal scarring and has anti-inflammatory activity and is primarily used for covering partial thickness burns until complete healing [7].

Amnion is primarily used for covering partial-thickness burns until complete healing.

The most important features of amniotic membrane can be divided to 4 categories:

- $\quad$ Rapid adherence to the wound bed.

- Increased angiogenesis.

- Inhibition of protease activity and PMN infiltration.

- $\quad$ Rapid re-epithelialization and promotion of wound healing.

These characteristics has guided researchers to use this magic \& cheep membrane as an adjunct to burn patients management and there are numerous researches on its benefits in acute burn wound management. We want to explain our new experiences in amniotic membrane administration on skin graft taking and also their early \& late advantages \& disadvantages in this group of burn patients .

\section{Amniotic membrane as a skin graft fixator, and graft take accelerator to Increase overall graft take in non-complicated wounds}

Amniotic membrane immediately adheres to the grafted areas \& fixes skin graft to their bed, which eliminates suturing on extremities and diminishes the need for suturing on other body parts. It also eliminates painful suture removal, accelerates graft take and decreases traumatic graft loss induced by suture removal.

The revascularization of a skin graft depends on immobilization of the graft on the wound bed. In cases where circular dressings are needed, the graft may be displaced under the dressing, leading to partial graft loss and several methods of graft fixation have been described $[7,8,9]$. A common technique is to use stitches but this is time consuming and the stitches need to be removed after graft take. Placing surgical drapes over the graft is another method but these must be removed on the second or third day when the grafts are still not well vascularised, and this can lead to graft failure. Fixation with skin staples was introduced as a fast and reliable method for graft fixation; [11]however it is expensive and stressful for the patient as these staples must be removed which can be painful and 
frightening, particularly for children. Forgotten staples are another troublesome complication. [12] (Fig 1a,b)

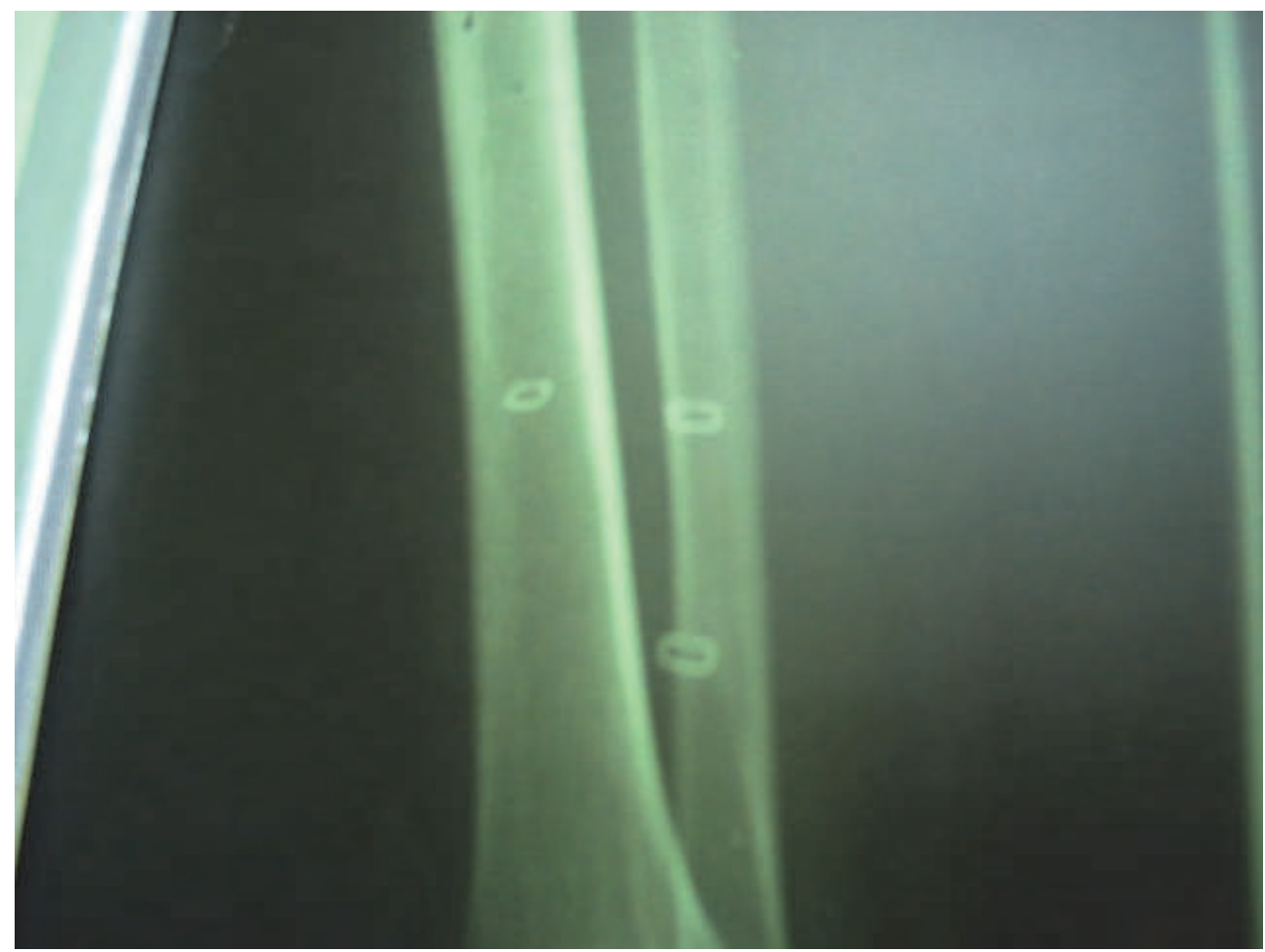

Fig. 1a. Incidental radiologic finding of multiple asymptomatic forgotten staples

Another technique uses steri-strip micro porous tapes for fixation, but the surrounding skin must be completely healthy to retain the tapes. [8] Other methods applying different materials such as honey [13] or cyanoacrylate [14] have been designed. We would like to present a method of graft fixation pioneered at our burn center and found convenient for both patient and surgeon, using amniotic membrane as fixator. This is particularly appropriate in children and also extremity burns. The skin graft is inserted on the wound bed, then covered with amniotic membrane (Fig. 2) and the dressing is applied.

The membrane adheres to the grafted area in a few minutes. There is no need for stitches or staples in extremities [15] or just a few anchoring sutures may be needed in some other body parts. [16]

Several studies have shown that the application of amniotic membrane as a graft fixator is accompanied by rapid re-epithelialization and healing $[2,16,17]$.Amniotic membrane has also been found an effective biological dressing for burns, as it diminishes the loss of plasma, fluid, protein and heat . [17], [18], [19] . 


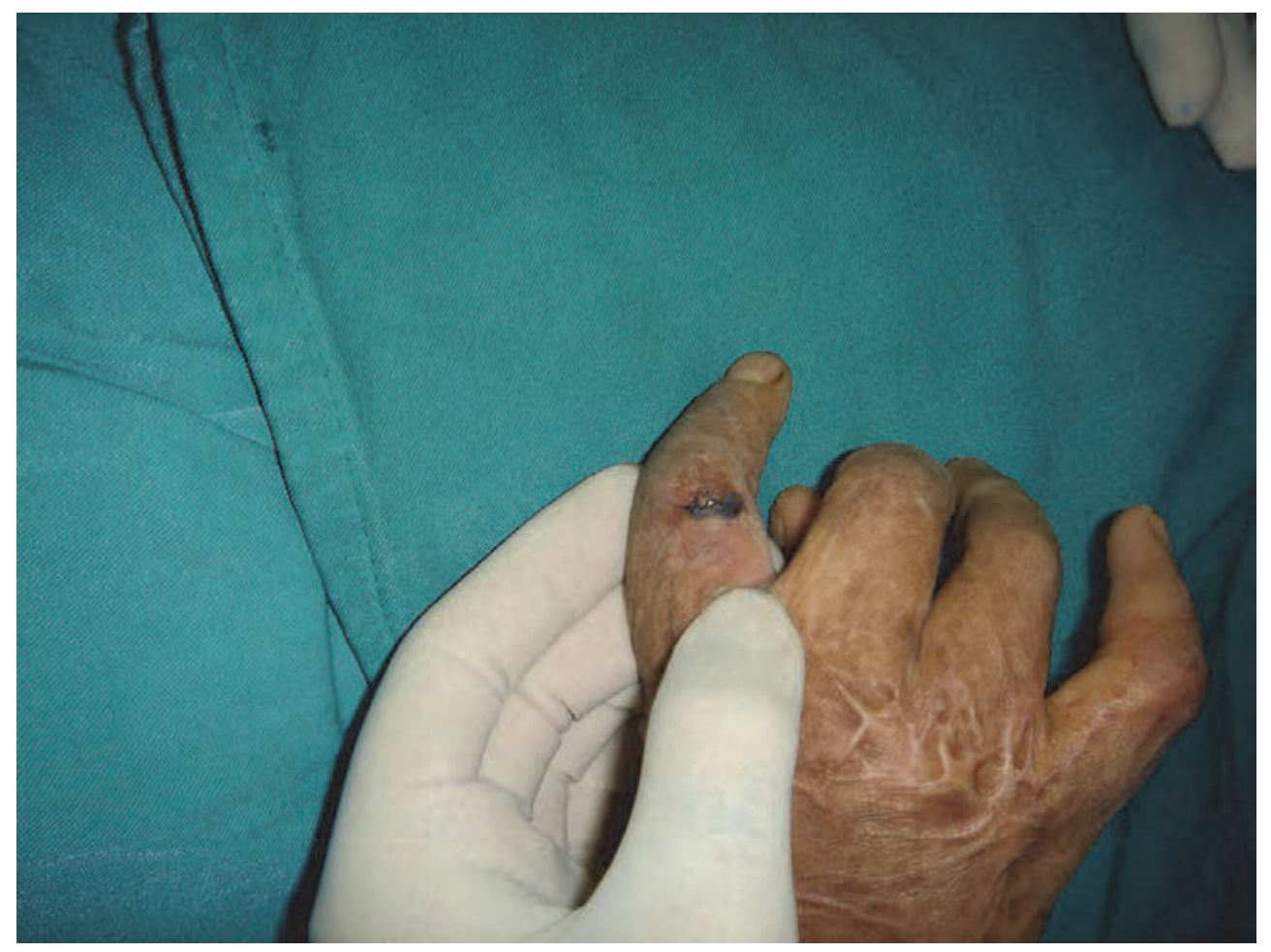

Fig. 1b. Painful forgotten staples removed 1 year after skin grafting. 


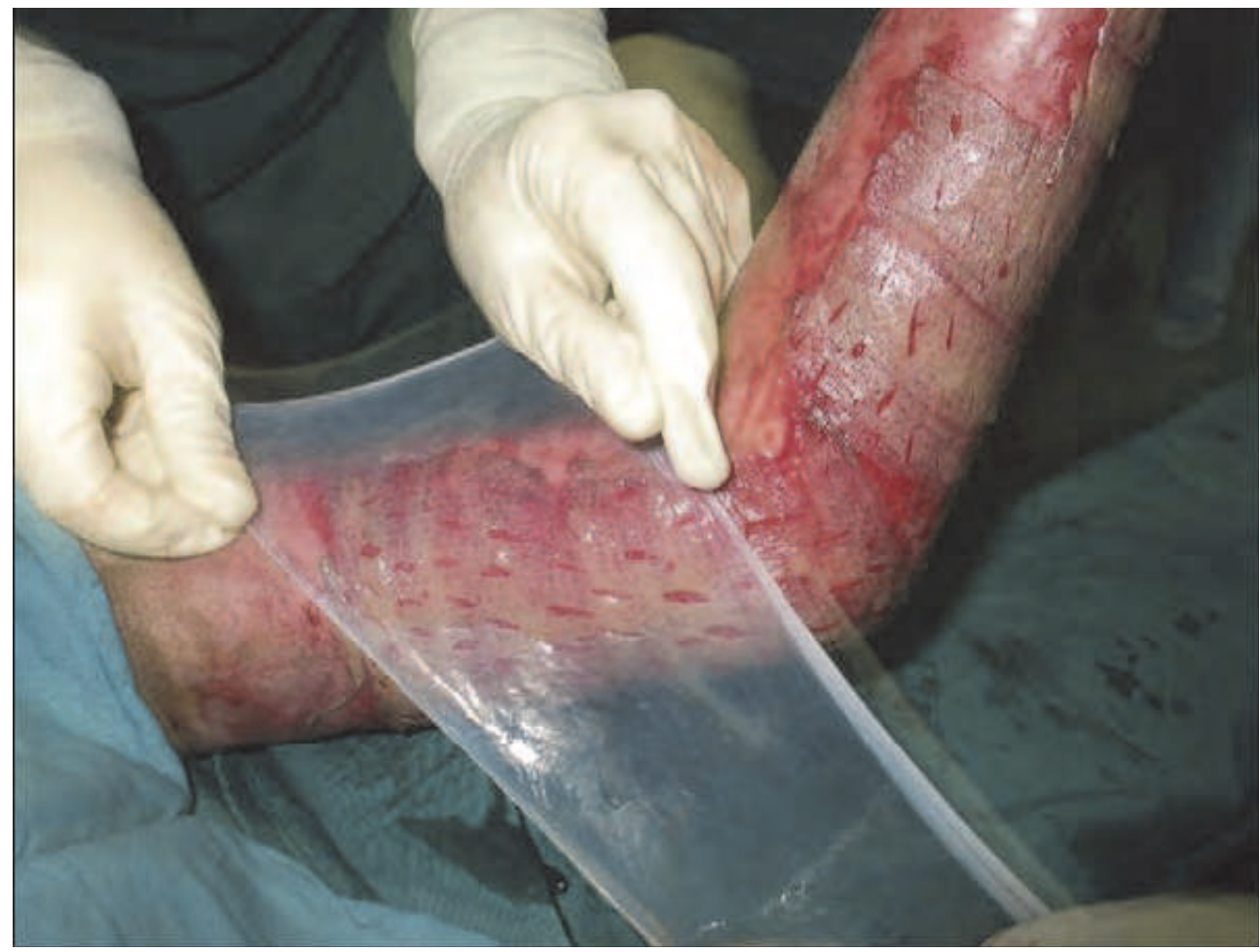

Fig. 2. Applying amniotic membrane for skin graft fixation.

In one study we evaluated the effect of amniotic membrane on rate of graft take. The patients were divided into two groups: 54 limbs in amnion group and 54 limbs in control group. The mean success rate of graft take was about $97 \%$ and mean graft take duration was about 7 days in amnion group (Fig 3) versus $89 \%$ and 14 days in control group respectively. Also this difference was statistically significant.

Our results show that amniotic membrane as skin graft fixator has no negative impact on graft take, but also significantly reduces the duration of complete graft take which is very important for both patient and health care system. Therefore, we recommend amniotic membrane as a skin graft fixator, and graft take accelerator to eliminate or diminish the need for painful and traumatizing postoperative dressing changes and thereby help to decrease the cost and also need for possible regrafting . 


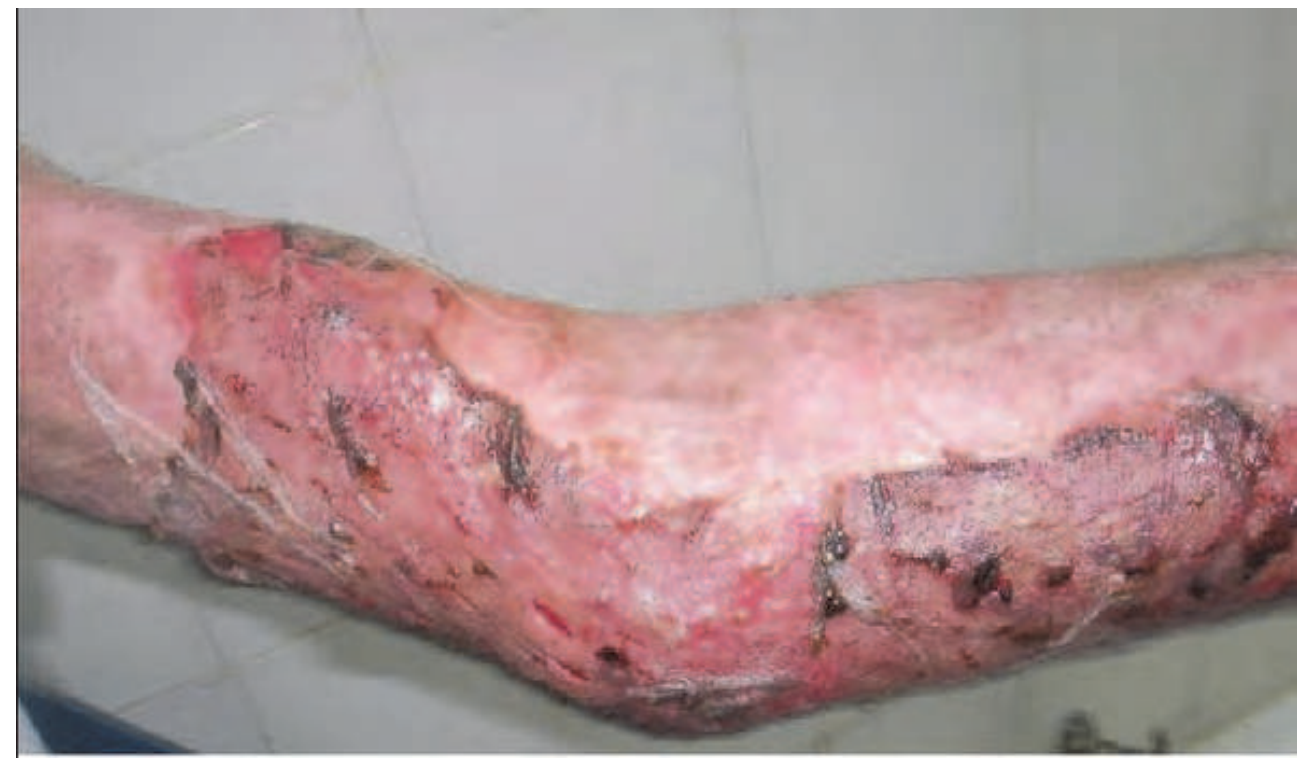

Fig. 3. The graft fixed with amniotic membrane, 5 days after procedure

\section{Acceleration of donor site healing}

Donor site morbidity including delayed and non-healing wounds and hypertrophic scar formation are major problems in skin grafted burn patients. Amniotic membrane dressing of skin graft donor sites, accelerates epithelialization and results in early wound closure, thereby, significantly reducing the risk of complications and eliminates postoperative dressing change.

Amnion have been used to cover clean partial-thickness wounds and donor sites, and applied as a temporary dressing for freshly excised burns.

It has advantages such as pain relief, prevention of infection, maintenance of a moist environment to promote healing, good adherence to wounds, and simple handling $[2,11$ 14]. Laboratory investigations have revealed that the basement membrane (BM) of amnion shares major BM components with human skin, and the BM zone resembles human skin, morphologically [17]. The epithelial side of denuded amnion has been shown to support the proliferation, spreading, and differentiation of corneal, mucousa and bronchial epithelial cells [18-20]. Furthermore, the stroma of amnion can serve as a dermal matrix in which fibroblasts show good adherence and proliferation [21, 22].

After cleansing the donor bed of blood, the amniotic membrane is applied (Fig 4) \& then covered with Vaseline gauze simple dressing. The amniotic membrane adheres to the wound bed and peels off, when the wound is completely epithelialized.

We studied 50 patients which had 2 similar donor sites of both lower exterimities. The mean healing time was about 6 days in amnion group and 13 days in control group, and pain was significantly lower in amnion group.

The desirable properties include rapid adherence, transparency, decreased patient discomfort and decrease in infection. One of the most important observations was that, 
amniotic membrane was used as a single application dressing. In all cases, it remained over the donor bed until healing was complete. This characteristic (single application) significantly reduces patient discomfort and costs by elimination the need for multiple dressing changes.

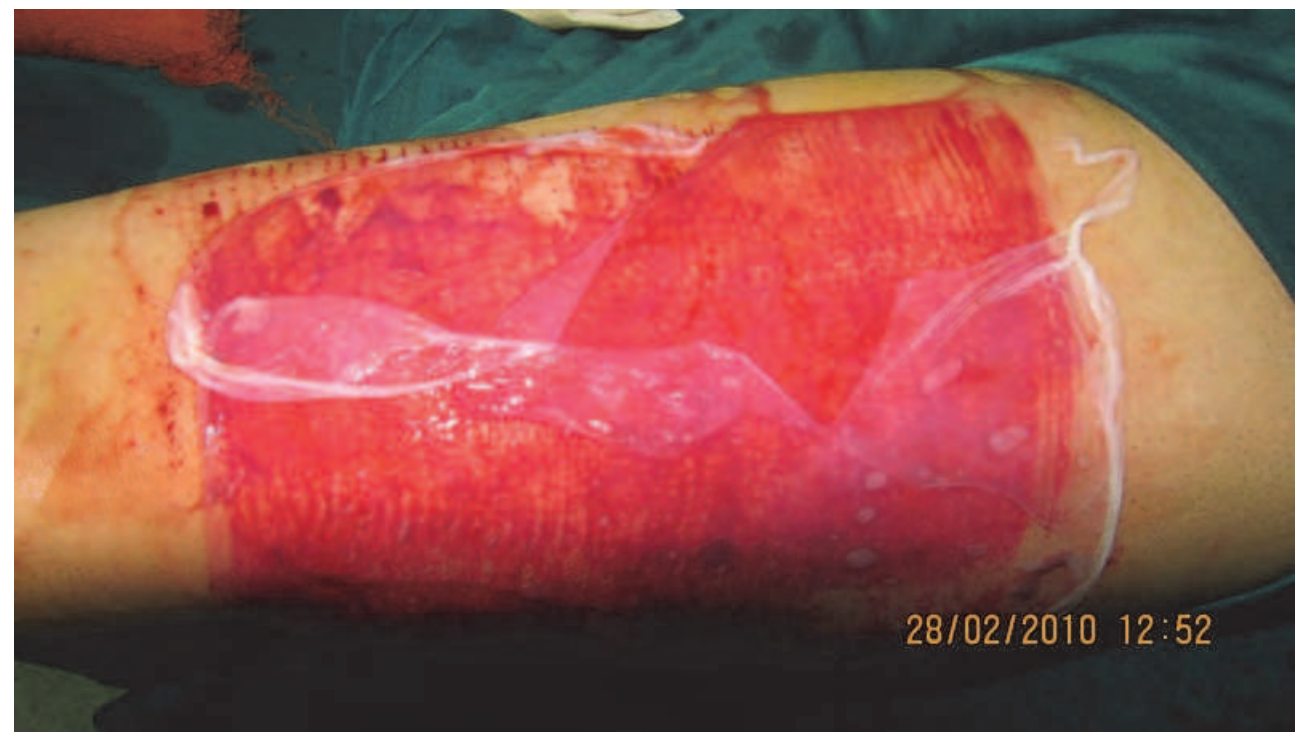

Fig. 4. Amniotic membrane dressing of donor site

Our clinical experience with amniotic membrane moved us to use this product widely for donor sites, especially in children.

\section{Increased graft take in old infected granulation tissue}

The standard treatment today for deep partial-thickness and full-thickness burns is early excision and grafting $(E \& G)$ but this technique may not be possible in centers with poor medical facilities. In these centers burn physicians should wait and see until the superficial burns heal primarily or granulation tissue appears in the base of the wound.

One problem in delayed grafting is the appearance of granulation tissue which, in addition to microbial colonization, reduces graft take and increases complications, mortality, hospital stay and costs. [20-32]

Old granulation tissue is a prevalent problem in developing countries. Management of these wound is very difficult, the result of skin grafting is poor and still there is no consensus about the best treatment modality of these wounds.

The problem which now arises is how to apply skin grafts on chronic granulation tissue and controversy continues on the best management.

Some surgeons favor application of graft after removal of granulation tissue while others favor application of grafts directly on the granulation tissue. We used amniotic membrane to manage these wounds in a clinical randomized control trial and observed good results. (not published) 
90 adult patients with old burn wounds (more than two weeks after granulation tissue appearance) and infected (according to the surgeon diagnosis and positive tissue cultures) were included in this study. (Fig 5).

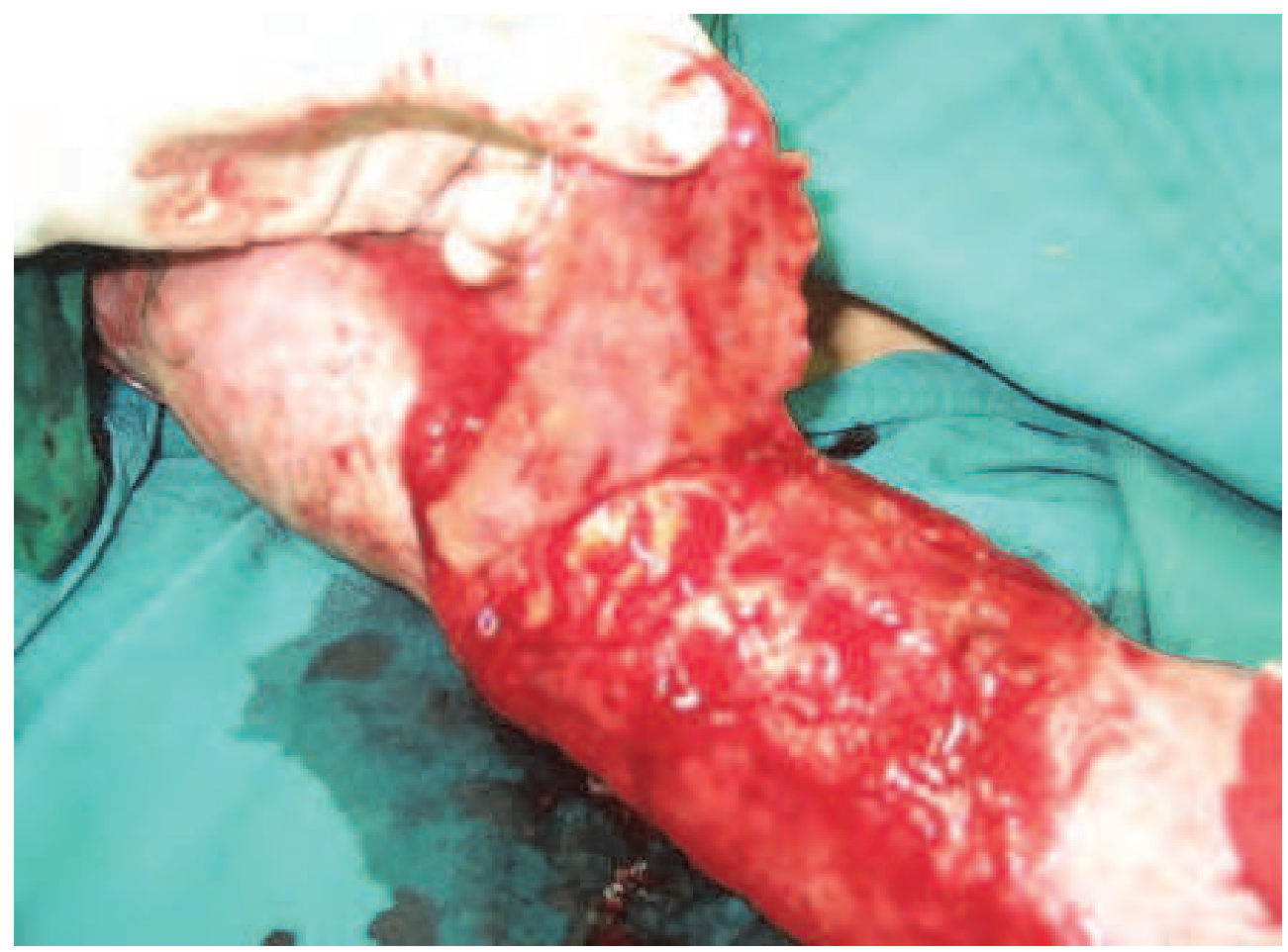

Fig. 5. Old granulation tissue in a burn patient (these wounds are shinny and easily removed with minimal digital pressure )

The most frequent bacterial isolate from burn wound culture was staphylococcus followed by pseudomonas. The most common cause of chronicity of burn wound was delay in referring of patient to burn center.

The extremities were randomly divided into two groups. Debridement of granulation tissue was performed in both groups. In group A, the graft surface was covered with amnion and in Group B( control group )skin grafting was performed in the conventional fashion.

Graft take was assessed on 14th post-grafting day.

The graft take was $90.13 \%$ in amnion group and $65.61 \%$ in control group that was statistically significant.$(\mathrm{p}$ value $<0.05)$

\section{Decreased hypertrophic scar and itching}

Hypertrophic scar and itching are disabling complications in burn patients. We studied \& saw interesting result with applying amniotic membrane on skin grafted areas in diminishing hypertrophic scar \& itching. This may be explained by accelerated wound healing \& epithelialization. 
Hypertrophic scarring after injuries, and especially burns, is a great concerns for patients and a challenging problem for clinicians.

Hypertrophic scars may cause significant functional and cosmetic impairment, and pruritus causes discomfort for the patient, and is responsible for decrease in quality of life. Pruritus causes discomfort and decreases quality of life .Hypertrophic scars result from general failure of normal wound healing processes. After burn injury, hypertrophic scars typically, appear on the trunk and extremities. [33]

Many factors such as race, age, genetic factors, hormone levels, atopy and immunologic responses of the individual patient appear to play a role. The type of injury, wound size and depth, anatomic region and mechanical tension on the wound are important as well. Also, complicating factors such as bacterial colonization and infection of the wound seem to induce hypertrophic scarring [34]. To predict the development of a hypertrophic scar in a burn wound, the time interval between burn and and healing is the most important factor and is closely related to depth and size of the wound [35].

Treatment of the hypertrophic scar still is a challenging issue due to the lack of effective treatments. Various treatments are currently available including surgical excision, steroid injection, radiation, laser therapy, silicone gels, calcium channel blockers and pressure therapy. Although management of hypertrophic scars has advanced in the past years, the lesions remain difficult to prevent and treat. Burn hypertrophic scars are often widespread and not linear. Although extensive research has led to an increase of knowledge in the pathophysiologic processes of wound healing and the formation of scars, but still there is no consensus regarding the best treatment to reduce or prevent hypertrophic scarring. Recurrences remain common and patient satisfaction is variable .

Optimal treatment of the burn wound is of eminent importance for wound healing and the prevention of hypertrophic scar formation. Deitch et al demonstrated that wound closure should be achieved within three weeks to reduce the risk for hypertrophic scar development [36]. Timing of grafting is still under debate, both for survival of the patients as well as the incidence and quality of hypertrophic scar. Adequate topical wound treatment allows for wound healing with controlled inflammation and should be applied to obtain fast wound closure. The autologous split thickness skin graft is still the mainstay of burn wound surgery. Although autologous split thickness skin graft may result in faster wound closure, it may not prevent hypertrophic scar formation in the operated area.

Several studies have shown that the application of amniotic membrane as a biological dressing in the management of burns is accompanied by rapid re-epithelialization and healing. Amniotic membrane has been found an effective biological dressing for burns, as it diminishes the oozing of plasma, bacterial count, and fluid, protein and heat loss [15-17].

In another study, we evaluated the effect of amniotic membrane as an adjunct in splitthickness skin graft on itching and hypertrophic scar formation in burn patients.(not published) This double blind randomized clinical controlled trial showed $59.25 \%$ decreased itching and $64.81 \%$ less hypertrophic scar formation in the skin grafted area covered with amniotic membrane in comparison to areas which managed by conventional skin grafting method.

This study showed that using amniotic membrane as an adjunct in split-thickness skin grafting significantly reduces post-burn itching and hypertrophic scar formation. It seems that additional research still is required to determine the best possible treatments. Since there is no optimum treatment option at present, amniotic membrane can be used as a novel 
modality in prevention rather than treatment of hypertrophic scar formation and itching in burn patients.

\section{Conclusion}

According to our experiences, amniotic membrane can strongly participate in skin grafted areas to improve skin graft take and decrease post graft complications.

\section{Acknowledgment}

I am grateful to the Shiraz burn research center staffs, ghotbeddin burn hospital physicians, caregivers and also countless burn patients for their invaluable helps, Hamed Ghoddusi Johari ,M.D for contribution in our research , (effect of amniotic membrane on skin graft take) and Mandana Kiasat Dolatabadi, M.D (effect of amniotic membrane on old infected granulation tissue ) as their thesis for degree on general of surgery and Shima Eskandari (effect of amniotic membrane on hyper trophic scare formation and itching ) as her thesis for degree of MD, Mr. Iman Ahrari ,medical student for their help in edition, Miss Zahra Moradi and Mrs. Masumeh Kherad for their special contribution in our researches, Mrs Zahra Jahedmah and Mrs. Mahbubeh Nazari for taking photographs .

\section{References}

[1] Mohammadi A.A, Sabet B, Riazi H, Tavakkolian A.R, Mohammadi M.K, Iranpak S. Amniotic Membrane Dressing: an Excellent Method for Outpatient Management of Burn Wounds. IJMS, Vol 34:1, 2009.161

[2] Ravishanker R, Bath A.S, Roy R. Amnion Bank- the use of long term glycerol preserved amniotic membranes in the management of superficial and superficial partial thickness burns. Burns 2003; 29: 369-74

[3] Robson MC, KrizekTJ, Koss N, Samburg JL. Amniotic membrane as a temporary wound dressing. Surg Gynaccol Obstet.1973; 136: 904-6.

[4] Hadjiiski O,Anatassov N. Amniotic membranes for temporary burn coverage. Annals of Burns and Fire Disasters. 1996; 10: 2-7

[5] Lorusso R, Geraci V, Masellis M. The treatment of superficial burns with biological and synthetic material: frozen amnion and biobrane . Annals of the MBC. 1989; $2: 2$-5

[6] SukariHalim A, Khoo T.L, Mohd. YussofSh.J.Biologic and synthetic skin substitutes: An overview .Indian J Plast Surg. 2010;43(Suppl): S23-S28

[7] Sangwan V.S, Burman S, Tejwani S, Mahesh S.P, Murthy R. Amniotic membrane transplantation: a review of current indications in the management of ophthalmic disorders. Indian J Ophthalmol. 2007; 55(4):251-60.

[8] Rudge R. An easy and safe method of split-thickness skin graft fixation. Burns 2007;33:1074-5

[9] Mah E, Morrison W.A. A stitch in time (Save Mines).Plast Reconstr Surg 2006;117:2535-6.

[10] Yenidu“ nya MO, O* zdengill E, Emsen I. Split-thickness skingraft fixation with surgical drape. Plast Reconstr Surg, 2000;106:1429-30.

[11] Alexander G, Al-Rasheed A.A. Skin stapler removal by artery forceps: a hazardous practice? Burns, 2005;31:116.

[12] Mohammadi, AA ，Ghoddusi johari, H . forgotten staples. Burns.2009; 35: 611 
[13] Ilteris Murat E. A different and safe method of split thickness skin graft fixation: medical honey application. Burns 2007;33:782-7.

[14] Adler N, Nachumovsky S, Meshulam-Derazon S, Ad-El D.Skin graft fixation with cyanoacrylate tissue adhesive in burn patients. Burns 2007;33:803

[15] Mohammadi AA, Ghoddusi Johari H. Amniotic membrane: A skin graft fixator convenient for both patient and surgeon. Burns 2008;34:1051-1052

[16] Mohammadi AA, Ghoddusi Johari H.Anchoring sutures:useful adjuncts for amniotic membrane for skin graft fixation in extensive burns and near the joints. Burns 2010;36:1134-1141

[17] Antasov W, Mazalova J, Todorod R, Stereva K, Trencheva W. Use of amniotic membrane as biological dressing in contemporary treatment of burn. Ann Medit Burns Club.1994;7:202-5.

[18] Sawhney C.P. Amniotic membrane as a biological dressing in the management of burns. Burns 1989;15:339-42.

[19] Haberl M, Oner Z, Bayraktar U, Bilgin N. The use of silver nitrate-incorporated amniotic membrane as a temporary dressing. Burns, 1987;13:159-63.

[20] Morykwas M.J, Thornton J.W, Bartlett R.H. Zeta potential of synthetic and biological skin substitutes: effects on initial adherence. Plast Reconstr Surg ,1987;79:732-9.

[21] Yang L, Shirakata Y, Tokumaru S, Xiuju D, Tohyama M, Hanakawa Y, et al. Living skin equivalents constructed using human amnions as a matrix. J Dermatol Sci.2009;56(3):188-95.

[22] Gajiwala K, Gajiwala AL. Evaluation of lyophilised, gamma-irradiated amnion as a biological dressing. Cell Tissue Bank 2004;5:73-80.

[23] QuinbyJr W.C, Hoover H.C, Scheflan M, Walters P.T, Slavin S.A, Bondoc CC. Clinical trials of amniotic membranes in burn wound care. Plast Reconstr Surg 1982; 70:711-7.

[24] Park M, Kim S, Kim I.S, Son D. Healing of a porcine burn wound dressed with human and bovine amniotic membranes. Wound Repair Regen 2008;16:520- 8.

[25] Oyama N, Bhogal B.S, Carrington P, Gratian M.J, Black M.M. Human placental amnion is a novel substrate for detecting autoantibodies in autoimmune bullous diseases by immunoblotting. Br J Dermatol 2003;148:939-44.

[26] Koizumi N, Fullwood NJ, Bairaktaris G, Inatomi T, Kinoshita S, Quantock AJ. Cultivation of corneal epithelial cells on intact and denuded human amniotic membrane. Invest Ophthalmol Vis Sci ,2000;41:2506-13.

[27] Nakamura T, Endo K, Cooper L.J, Fullwood N.J, Tanifuji N, Tsuzuki M, et al. The successful culture and autologous transplantation of rabbit oral mucosal epithelial cells on amniotic membrane. Invest Ophthalmol Vis Sci 2003;44: 106-16.

[28] Sakamoto T, Hirano K, Morishima Y, Masuyama K, Ishii Y, Nomura A, et al. Maintenance of the differentiated type II cell characteristics by culture on an acellular human amnion membrane. In Vitro Cell Dev Biol Anim 2001;37:471-

[29] Solomon A, Wajngarten M, Alviano F, Anteby I, Elchalal U, Pe'er J, et al. Suppression of inflammatory and fibrotic responses in allergic inflammation by the amniotic membrane stromal matrix. Clin Exp Allergy 2005;35:941-8.

[30] Burman S, Tejwani S, Vemuganti G.K, Gopinathan U, Sangwan V.S. Ophthalmic applications of preserved human amniotic membrane: a review of current indications. Cell Tissue Bank 2004;5:161-75. 
[31] Fred W. Endof and Nicole S. Gibran .In: Brunicardi FC, Anderson DK, Billiar TR, Dunn DL, Hunter JG, Pollock RE. editors Schwartz's principles of Surgery. New York: MacGraw - Hill; 2010.p.197- 207.

[32] Sanjay D ,Rakesh D, Anand K and Bhavani R. Comparative study of skin grafting with and without surgical removal of granulation tissue in chronic burn wounds . Burns .2007; 33:872-878

[33] Ozbek S, Ozgenel Y, Etoz A, Akin S, Kahveci R, Heper Y, ErcanI, Ozcan M. The effect of delayed admission in burn centers on wound contamination and infection rates. Ulus Travma Acilcerrahi Derg. 2005; 11(3) : 230-7.

[34] Bloemen M.C, van der Veer W.M, Ulrich M.M, van Zuijlen P.P, Niessen F.B, Middelkoop E. Prevention and curative management of hypertrophic scar formation. Burns 2009; 35: 463-475.

[35] Niessen F.B, Spauwen P.H, Schalkwijk J, Kon M. On the nature of hypertrophic scars and keloids: a review. Plast Reconstr Surg 1999;104(5):1435-58.

[36] Cubison T.C, Pape S.A, Parkhouse N. Evidence for the link between healing time and the development of hypertrophic scars (HTS) in paediatric burns due to scald injury. Burns 2006;32(8):992-9. 


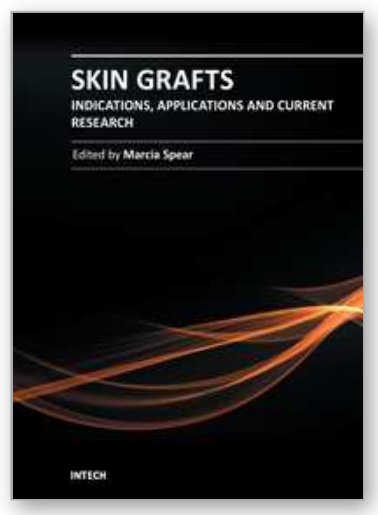

\author{
Skin Grafts - Indications, Applications and Current Research \\ Edited by Dr. Marcia Spear
}

ISBN 978-953-307-509-9

Hard cover, 368 pages

Publisher InTech

Published online 29, August, 2011

Published in print edition August, 2011

The procedure of skin grafting has been performed since 3000BC and with the aid of modern technology has evolved through the years. While the development of new techniques and devices has significantly improved the functional as well as the aesthetic results from skin grafting, the fundamentals of skin grafting have remained the same, a healthy vascular granulating wound bed free of infection. Adherence to the recipient bed is the most important factor in skin graft survival and research continues introducing new techniques that promote this process. Biological and synthetic skin substitutes have also provided better treatment options as well as HLA tissue typing and the use of growth factors. Even today, skin grafts remain the most common and least invasive procedure for the closure of soft tissue defects but the quest for perfection continues.

\title{
How to reference
}

In order to correctly reference this scholarly work, feel free to copy and paste the following:

Ali Akbar Mohammadi and Mohammad Kazem Mohammadi (2011). How Does Human Amniotic Membrane Help Major Burn Patients Who Need Skin Grafting: New Experiences, Skin Grafts - Indications, Applications and Current Research, Dr. Marcia Spear (Ed.), ISBN: 978-953-307-509-9, InTech, Available from: http://www.intechopen.com/books/skin-grafts-indications-applications-and-current-research/how-does-humanamniotic-membrane-help-major-burn-patients-who-need-skin-grafting-new-experiences

\section{INTECH}

open science | open minds

\author{
InTech Europe \\ University Campus STeP Ri \\ Slavka Krautzeka 83/A \\ 51000 Rijeka, Croatia \\ Phone: +385 (51) 770447 \\ Fax: +385 (51) 686166 \\ www.intechopen.com
}

\author{
InTech China \\ Unit 405, Office Block, Hotel Equatorial Shanghai \\ No.65, Yan An Road (West), Shanghai, 200040, China \\ 中国上海市延安西路65号上海国际贵都大饭店办公楼 405 单元 \\ Phone: +86-21-62489820 \\ Fax: +86-21-62489821
}


(C) 2011 The Author(s). Licensee IntechOpen. This chapter is distributed under the terms of the Creative Commons Attribution-NonCommercialShareAlike-3.0 License, which permits use, distribution and reproduction for non-commercial purposes, provided the original is properly cited and derivative works building on this content are distributed under the same license. 